\title{
Needs for Post-hospital Education among Parents of Infants and Toddlers with Congenital Heart Disease
}

\author{
Bo Ryeong Lee ${ }^{1}$, Hyun Young Koo ${ }^{2}$ \\ ${ }^{1}$ Master's Student, College of Nursing, Daegu Catholic University, Daegu; ${ }^{2}$ Professor, College of Nursing • Research Institute of Nursing Science, Daegu Catholic \\ University, Daegu, Korea
}

Purpose: This study was conducted to investigate the educational needs of parents of infants and toddlers with congenital heart disease (CHD) after hospital discharge. Methods: Qualitative content analysis was conducted of in-depth interviews of eight parents, and the results of an online survey of 171 parents were analyzed quantitatively. Results: Only $16.4 \%$ of parents reported that they had received education after hospital discharge on how to provide care for a child with CHD at home. The main reason why parents did not receive education on this topic was that they did not have sufficient opportunities or information (75.5\%). In addition, $97.1 \%$ of parents stated that they needed educational programs that would be available at home after discharge. In terms of specific educational content, parents expressed the highest needs for education on the symptoms of CHD and ways to cope with them, the prognosis of CHD, and the growth and development of infants and toddlers with CHD. Conclusion: The study showed that parents' educational needs were high in many ways. However, the information and educational opportunities offered after discharge were insufficient compared to those needs. Further research is needed to develop post-hospital educational programs that meet their needs.

Key words: Caregivers; Congenital heart defects; Discharge; Education; Home care

\author{
Corresponding author Hyun Young Koo \\ https://orcid.org/0000-0001-5848-2143 \\ College of Nursing, Daegu Catholic University, \\ 33 Duryugongwon-ro, 17gil, Nam-gu, Daegu 42472, Korea \\ TEL +82-53-650-4829 FAX +82-53-650-4392 \\ E-MAIL hykoo@cu.ac.kr \\ * This article was adapted from a thesis by Bo Ryeong Lee in partial fulfillment \\ of the requirements for the master's degree at Daegu Catholic University.
}

Received Dec 17, 2019 Revised Jan 3, 2020 Accepted Jan 3, 2020
(9) This is an Open Access article distributed under the terms of the Creative Commons Attribution NonCommercial License (http://creativecommons.org/licenses/by-nc/4.0/) which permits unrestricted noncommercial use, distribution, and reproduction in any medium, provided the original work is properly cited.

\section{INTRODUCTION}

Congenital heart disease (CHD) is the most common type of congenital disease [1]. According to statistical data from the Korea Heart Foundation, around 5,000 people undergo surgery for CHD each year in South Korea, and the post-surgery mortality rate improved from an average of $3.8 \%$ in the early 2000 s to $1.2 \%$ in 2018 [2]. This improvement in the post-surgery mortality rate is attributed to the development of non-invasive diagnostic technology, changes in treatment guidelines that incorporate early interventions, and professional and systematic postoperative management [3]. As a result, the number of children who grow up with CHD has increased [1]. Accordingly, the focus is shifting from treatment aiming to achieve survival in children with CHD to management of their long-term outcomes, and research is being conducted on how CHD affects the quality of life of children with CHD and their families [4]. A systematic review on children with CHD reported that parenting style, social support, and coping strategies were associated with quality of life in children with CHD [5]. In particular, parents are the most important source of support for children with CHD, and studies have reported 
that parents directly influence the health of children with CHD [6,7]. Therefore, to promote healthy growth and development in children with CHD, it is necessary to provide adequate support to their parents and to enhance their parents' coping abilities.

The standard treatment of CHD has changed from palliative care to early interventions [3]. As a result, most children with $\mathrm{CHD}$ experience their first therapeutic intervention in the postpartum period (defined as 6 to 8 weeks after delivery), which is a time when parents tend to focus on their children's survival [8]. Parents then face a situation where they must continue to manage their children's disease after discharge from the hospital [9], because infants and toddlers with CHD continue to experience difficulties in activities ranging from feeding to sleeping due to symptoms of dyspnea, hypoxia, and heart failure that remain after initial treatment [9-12]. Therefore, parents may experience psychological distress due to their unfamiliarity with managing their children's disease and their children's uncertain prospects [8,10-12], which might lead to a dysfunctional parenting style that interferes with their children's healthy growth and development [4].

According to a previous study in South Korea, parents of children with CHD had high levels of stress and educational needs for the post-hospital period on how to nurture and provide care for their children [12,13]. Receiving information about their children's disease reduced parenting stress by promoting positive coping behaviors [14] and helped parents to accept their children's condition by reducing the powerlessness that parents felt towards the disease [15]. Providing information to the parents of infants and toddlers with CHD reduces their parenting burden and improves their parenting skills [16]. Children of parents who received adequate information had fewer complications such as surgical wound infections [6]. Thus, it is necessary to provide information to parents on a regular basis until their infants and toddlers with CHD fully recover at home [16]. The parents of infants and toddlers with CHD experience stress due to a sense of powerlessness, as they feel that they are unable to protect or help their young children; however, as their knowledge and skills improve, they become able to care for their children more skillfully [7]. Therefore, ongoing informational support is important.

The educational materials that have been developed in South Korea thus far have generally consisted of content provided during hospitalization, and do not contain adequate information for parents to take care of children with CHD post-discharge [12,17]. These materials are in the form of pamphlets that are provided a single time at the hospital and cover the entirety of childhood; as such, they are inadequate for parental education specific to the developmental stages of in- fancy and early childhood [12,17]. The criterion for considering parental needs for education to have been met should not be the belief of medical staff that parents have received the necessary information, but the feeling of parents themselves that they have received important information [18]. Studies have investigated the post-hospital needs of parents of infants and toddlers with CHD in other nations [11,16,18], but in South Korea, prior research has only been conducted among parents of currently-hospitalized children with CHD [13]. Since parents may not be cognizant of their needs before they start to care for their infants and toddlers with CHD at home [19], it is necessary to confirm the educational needs of parents of infants and toddlers with CHD who are at home after being discharged from the hospital.

This study aimed to identify the preferred educational methods and content among parents caring for infants and toddlers with CHD after discharge. The purpose of this study was to elicit information on the educational needs of parents of infants and toddlers with CHD after discharge. Since previous research on this topic is lacking in South Korea, this study comprehensively explored parents' educational needs, first through in-depth interviews and then through an online survey. The results of this study may be used as a foundation for developing an educational program for parents of infants and toddlers with CHD after hospital discharge.

\section{METHODS}

\section{Research Design}

This study utilized a descriptive research design that combined a qualitative content analysis of in-depth interviews and a quantitative analysis of responses to an online survey, which aimed to identify needs for post-hospital education among parents of infants and toddlers with CHD.

\section{Subjects}

The population of this study comprised 171 parents of infants or toddlers (aged 3 years or younger) with CHD who were caring for their children at home after discharge from the hospital. Parents were excluded from the study if their child 1) did not meet the age criterion, 2) had another major deformity or disability, or 3) was currently hospitalized.

Participants in the in-depth interviews were recruited both online and offline, while all participants for the online survey were recruited online. Online recruitment was conducted through a participant recruitment post on "Mom Café," an online community, the administrators of which granted permission for recruitment after receiving an explanation of the pur- 
pose and procedure of the study. Offline recruitment occurred at a tertiary hospital after obtaining permission from the department chair and nurse in charge of the Department of Pediatric Thoracic and Cardiovascular Surgery. With the help of the nurse in charge, parents of infants and toddlers with CHD who visited the hospital for outpatient treatment were recruited to the study.

In-depth interviews were conducted until saturation was reached and no additional information was obtained. In-depth interviews were conducted with eight parents. For the online survey, the minimum sample size for an analysis of variance (ANOVA) model was calculated using a statistical program (G*Power 3.1.7), setting the effect size as .25, the $\alpha$ error probability as .05 , and the power as .80 . The calculated minimum sample size was 159 , and considering an expected drop-out rate of $10 \%, 175$ participants were recruited for the survey. The final sample size was 171, after four incomplete responses were discarded.

\section{Research Methods}

\section{1) In-depth interviews}

The in-depth interviews were conducted first, as a preliminary exploration of parents' post-discharge educational needs. The in-depth interviews used a qualitative descriptive approach [20], which comprehensively summarizes honest stories told from a daily perspective without any specific philosophical or theoretical framework. Participants were asked about their opinions and experiences regarding education (information) on ways to manage their children's CHD after discharge from the hospital. The following open-ended questions were asked: "Have you received education (information) about managing your child's CHD after hospital discharge? How was that experience?", "What did you think about the education (information) on managing your child's CHD after hospital discharge?", "Where do you usually get educational materials (information) on managing your child's CHD after hospital discharge? What are the educational materials (information) that you usually receive and you would like to receive in the future?", and "If an educational program for managing children's CHD after hospital discharge were to be developed, what aspects do you think would be needed?". Indepth interviews were conducted from July 15 to August 15, 2019. Each participant was interviewed once, and the duration of the interviews ranged from 45 to 70 minutes. The indepth interviews were audio-recorded, and field notes were written on the interview interactions, participants' facial expressions and attitudes, and other noteworthy aspects of the interview.

\section{2) Online survey}

To obtain quantitative insights into parents' needs for posthospital education, an online survey was conducted from September 12 to October 4, 2019. In order to increase accessibility for stay-at-home parents, an online survey was created on Google Surveys. The survey form was developed according to the procedure described below.

\section{(1) First round of item construction}

Based on the results of the in-depth interviews, as well as an analysis of 16 related articles and six related websites from South Korea and abroad, the preliminary items were written. The survey consisted of five items on experiences of education, four items on preferences for education, and 60 items in 14 categories on educational needs by informational content. The 60 items on educational needs by informational content were rated on a 4-point Likert scale, with 1 being "not necessary at all" and 4 being "very necessary".

(2) Content validity verification and second round of item construction

An expert panel of 10 individuals that consisted of two pediatric nursing professors, one cardiologist from the Division of Pediatrics, one cardiac surgeon specializing in pediatric thoracic and cardiovascular surgery, one nurse in charge at the Department of Pediatric Thoracic and Cardiovascular Surgery, two nurse practitioners at a pediatric cardiovascular center, and three pediatric cardiology nurses with more than 5 years of experience in pediatric cardiology validated the content of the 60 items that surveyed educational needs by informational content. Fifty-three items that had a content validity index (CVI) of .80 or higher were selected. Three items that had a CVI of .75 .78, but were frequently mentioned by the participants of in-depth interviews, were added after considering experts' opinions. As a result, the second draft of the survey included five items on experiences of education, four items on educational preferences, and 56 items in 13 categories on educational needs according to informational content.

(3) Final round of item construction based on pilot surveys A pilot study was conducted among 30 parents who looked after infants and toddlers with CHD at home. It took around 15 minutes for participants to complete the survey, and 80.0 $96.7 \%$ of the participants responded that their understanding of the survey items, the length of the items, the font and font size, and the 4-point Likert scale were adequate. Participants were asked to respond with additional comments if they had any other questions on symptoms or informational content in the section on educational needs by informational content. The additional comments made could be classified as items 
about the prognosis of CHD, symptoms and responses of $\mathrm{CHD}$, and the growth and development of infants and toddlers with CHD. Therefore, no revisions were made to the items in the second draft. A free response item eliciting additional comments about educational needs by informational content was added, and the final survey contained five items on experiences of education, four items on educational preferences, and 57 items in 13 categories on educational needs by informational content. The Cronbach's $\alpha$ of the survey was .96 in the pilot survey and .96 in the main survey.

\section{Data Analysis}

\section{1) In-depth interview}

The interview data were analyzed according to the procedure used for inductive content analysis [21]: preparation, organizing, and reporting. In the preparation stage, audio recordings were transcribed and meaningful words, expressions, sentences, and paragraphs were extracted in order to select the unit of analysis. In the organizing stage, open codes were generated based on the selected unit of analysis and grouped by categories. In the reporting stage, each category was explained and described.

\section{2) Online survey}

The collected data were analyzed using SPSS version 25.0 (IBM Corp., Armonk, NY, USA). Descriptive statistics (frequency, percentile, mean, and standard deviation) were calculated for the general characteristics of the study participants and their educational needs. Differences in educational needs by general characteristics were tested using the t-test and ANOVA. The Scheffé test was used for post-hoc multiple comparisons.

\section{Ethical Considerations}

In order to ensure that standards for research ethics were met, this study was approved by the Institutional Review Board of D University prior to data collection (CUIRB-20190031). Participants were included in the study after they read the consent form, chose to participate voluntarily in the research, and provided either written or online consent. The first page of the online survey was the consent form. In an item located below the consent form, participants were asked to type in their name if they consented to participate in the study. Only participants who provided consent could move onto the first page of the survey. Participants were provided an explanation of the purpose and method of the study, anonymity and data privacy, the right to withdraw from the study at any point, and disposal of data if the study is terminated. It was also explained that the collected data would not be used for other purposes, and any data that participants did not wish to be included in the study would not be used. Data collection and analysis followed guidelines on research ethics, and no participants withdrew from the study.

\section{RESULTS}

\section{Results of the In-depth Interviews on Educational Needs for Managing Their Children's Disease after Hospital Discharge}

Table 1 shows the general characteristics of the in-depth interview participants. The needs expressed by participants in the in-depth interviews for education on how to manage their children's disease after hospital discharge could be divided into 1) their needs for education to be provided and 2) their needs for educational content.

Table 1. General Characteristics of the Participants in In-depth Interviews

$(N=8)$

\begin{tabular}{|c|c|c|c|c|c|c|c|}
\hline \multirow{2}{*}{ No } & \multirow{2}{*}{ Relationship } & \multirow{2}{*}{ Age } & \multirow{2}{*}{ Occupation } & \multirow{2}{*}{$\begin{array}{c}\text { Number of } \\
\text { children }\end{array}$} & \multicolumn{3}{|c|}{ Children with CHD } \\
\hline & & & & & Age* $^{*}$ sex & Birth order & CHD \\
\hline 1 & Mother & 42 & Housewife & 1 & $18 / \mathrm{M}$ & 1 & TAPVC \\
\hline 2 & Mother & 38 & Housewife & 4 & $22 / F$ & 4 & MR \\
\hline 3 & Mother & 33 & Housewife & 2 & $30 / \mathrm{M}$ & 1 & TOF \\
\hline 4 & Mother & 27 & Nurse & 2 & $14 / \mathrm{M}$ & 2 & TAPVC \\
\hline 5 & Mother & 22 & Instructor & 3 & $25 / F$ & 3 & DORV \\
\hline 6 & Mother & 32 & Researcher & 2 & $20 / M$ & 1 & TGA \\
\hline 7 & Mother & 27 & Service worker & 2 & $27 / M$ & 1 & VSD \\
\hline 8 & Mother & 30 & Housewife & 2 & $11 / \mathrm{M}$ & 1 & DORV \\
\hline
\end{tabular}

*Month; $\mathrm{CHD}=$ Congenital heart disease; TAPVC=Total anomalous pulmonary venous connection; $\mathrm{MR}=\mathrm{Mitral}$ regurgitation; $\mathrm{TOF}=\mathrm{Tetralogy}$ of Fallot; DORV=Double outlet right ventricle; TGA=Transposition of great arteries; VSD=Ventricular septal defect. 


\section{1) Needs for education to be provided}

Participants discussed their needs for education to be provided on how to manage their children's disease after hospital discharge, and expressed that they needed reliable, easy-tounderstand, open and accessible, and visual information. In addition, participants suggested that it would be helpful to hear stories from parents of children with similar main diagnoses and circumstances or to receive information about cases.

[The need for reliable information] I personally think it would be great if there could be a lot of different (reliable) information since it's hard to check whether this or that information is verifiable or reliable. (Participant 5)

[The need for easy-to-understand information] I would like it if the information could be both professional and easy enough for mothers raising children to understand, not just for medical staff. Stories from other mothers would be helpful and nice, but I would prefer to refer to resources providing information, rather than looking around here and there. (Participant 7)

[The need for accessible education] When I try to read a book on this issue, they are all too technical. I don't have the mental space to check books out from the librar $y$...When you look at babies with heart conditions, there are more babies who receive surgery when they are very little. I don't have the mental space to think about those things. I don't feel like it's possible to read books. Since matters are urgent, I just pick up my phone and look things up (online), so that's what I do first. (Participant 1)

[The need for open information] You need to sign up to view information online. There is a little bit of a psychological burden when it comes to signing up, even for someone like me, a mother with a child with a heart condition. How should I say this? (The website) should give a bit of information first, but the information is all blocked. I couldn't get any information from there. (Participant 3).

[The need for visual information] More pictures. I can't read long sentences when my baby is sick. I try to read, but I keep thinking about my sick baby, so I just skim and the content goes over my head. I think pictures would be easier to look at and understand. I search for information in the text, but I feel anxious. I just read it once. Information doesn't stick in my head. (Participant 4)

[The need for similar cases] I strongly prefer to read about experiences, cases. (...) Medical information becomes more complicated as you search more. Medical information should be short, and I think experiences, cases, and prognoses are better. (Participant 4)

\section{2) Needs for educational content}

Participants discussed various elements of educational content that they needed, and their responses were organized into the following 10 categories: general aspects about CHD, prognosis of $\mathrm{CHD}$, surgical wound management, characteristics and symptoms of infants and toddlers with CHD, medication, feeding and nutrition, development and rehabilitation, physical activity, medical devices used at home, and emergency situations and responses.

[General aspects about CHD] There is no need for many people to know about heart disease, but when I type in "total anomalous pulmonary venous connection" online, there is no information. An encyclopedia contains an explanation of what this is. After my baby had surgery, I found and read the entry again. Even after hearing about the condition so much, as I read, I think "So what is going on? What is wrong with my baby?" (Participant 1)

[Prognosis of CHD] There is no information about this. I felt more anxious because I've never seen information saying that this kind of child was okay after this kind of a procedure. Around me, I only see information on common conditions like ventricular septal defect, I don't have any information. Since those conditions are more common, there's more information for mothers of babies with common conditions. I didn't know what the prognosis of my baby's condition was, so I was more nervous. (Participant 4)

[Surgical wound management] At the time of the first round of surgery, it was hard to tape the open heart surgery wound. After I give the child a bath at home, I disinfect the wound, and there's a tape that the hospital recommended. Steri- something $\cdots$ I put that tape on the wound. I heard you should gather the skin around the wound. I didn't do that (managing the wound) in the hospital, so that was difficult for me. (Participant 5)

[Characteristics and symptoms of infants and toddlers with CHD] They told us to come to the hospital if the baby shows signs of cyanosis. I don't know what cyanosis is. I looked it up, and it says cyanosis is when the lips turn blue. What does it look like when lips turn blue? What shade of blue? I don't know these things. What is cyanosis? On the internet, it just says lips turning blue like it's obvious. I just feel "How can the baby's lips turn blue?"(Participant 1)

[Medication] About medications, effects, and precautions? For example, food. Babies can also receive cold medication, so can I give the baby a certain medication at the same time as cold medication? It would be good to have information on what kinds of medication shouldn't 
be combined, what are the precautions, and what are some side effects. (Participant 7)

[Feeding and nutrition] I was most curious about food. The baby only consumed a very small amount at feedings '. At our regular check-ups, I asked a lot, "The baby does not eat very well. There is a little bit of blood leaking. Could that be the reason?"(Participant 6)

[Development and rehabilitation] At the regular checkups, we found out that our baby wasn't holding her head up when she was supposed to or was late in reaching some developmental milestones. So we were connected to rehabilitation treatments. (Other parents) had similar experiences. A lot of parents whose babies had surgery very early on asked about babies flipping over or holding their heads up through social networking services (SNS). A lot of questions were asked about price, frequency, and effectiveness (of rehabilitation treatments). (Participant 5)

[Physical activity] What I'm most curious about, when I search online, it says that it's important to do physical activity. It says no child dies while exercising. Then I also hear some doctors say not to do any physical activity at all, so ‥ I'm a mom, so I don't want to raise my child differently from other children. But the grandparents say "the child was born sick, the child is sick..." so they don't allow the child to do anything. (Participant 6)

[Medical devices used at home] There is such a wide range when it comes to medical devices (nebulizers). They need to be sterilized and washed to be properly maintained, but I don't know how to do that. It would be great to use disinfectants like in the hospital, but it's so hard for us to buy them. (Participant 4)

[Emergency situations and responses] The child could have some problems, and when those problems occur, I won't know how to respond. Right now, I think I need that information. If there's an accident, the hospital should have basic information about the child, but hospitals don't share information with each other. So what should we tell them about the child? (Participant 6)

\section{Results of the Online Survey on Educational Needs for Managing Their Children's Disease after Hospital Dis- charge}

\section{1) Educational needs by general characteristics}

Nearly three-quarters $(74.3 \%$; $=127)$ of the survey participants were mothers, and the fathers accounted for the remaining $25.7 \%(n=44)$. Furthermore, $78.9 \%(n=135)$ of participants were in their 30s, and $56.7 \%(n=97)$ had a bachelor's degree. The majority of participants $(62.6 \%$; $=107)$ were not employed, and $61.4 \%(n=105)$ had only one child. No significant difference in educational needs was found according to any of the participants' general characteristics (Table 2).

In terms of the general and disease-related characteristics of the participants' infants and toddlers with $\mathrm{CHD}, 50.9 \%(\mathrm{n}=87)$ were boys, and $49.1 \%(n=84)$ were girls. Most of the children $(81.3 \% ; n=139)$ were toddlers, while $18.7 \%(n=32)$ were in infancy. Acyanotic CHD was present in $69.0 \%(n=109)$ of the children, while $31.0 \%(n=49)$ had cyanotic CHD. Some differences were found in educational needs according to the child's disease-related characteristics. Educational needs were higher among parents of children with cyanotic CHD than among parents of children with acyanotic $\mathrm{CHD}(\mathrm{t}=2.38$, $p=.019$ ) and were higher among parents whose children had received two or more treatment interventions than among parents whose children had received one or no treatment intervention $(\mathrm{F}=7.83, p=.001)$. Educational needs were also higher among parents if their children first underwent treatment or surgery as a newborn than if they first underwent treatment or surgery as a toddler $(\mathrm{F}=4.82, p=.010)$, if their children were on medication than if they were not on medication $(\mathrm{t}=4.90$, $p<.001$ ), and if additional treatment or surgery was scheduled than if when none was scheduled or the timing of the next treatment was unknown $(\mathrm{F}=7.66, p=.001)$ (Table 2).

\section{2) Experiences of education on managing their children's dis- ease after hospital discharge}

Only $16.4 \%(n=28)$ of participants reported that they had received education on managing their children's disease after hospital discharge. Among those who reported previously receiving education on this topic, $53.6 \%(n=15)$ had received education from hospital websites or heart foundation websites, $42.9 \%(n=12)$ from blogs and online communities, 35.7\%(n=10) each from YouTube and via offline large-group education, and $32.1 \%(n=9)$ on SNS. The most satisfactory source of information was offline large-group education for $21.5 \%(n=6)$ of the participants, while $14.3 \%(n=4)$ each selected offline small-group education, offline one-on- one education, and hospital websites or heart foundation websites. The average satisfaction score for the education that they had received was $2.89 \pm 0.57$ (Table 3).

The majority $(83.6 \%$; $=143)$ of parents had not received education on managing their children's disease after hospital discharge. Some of the reasons that they reported for not having received any education on this topic were "No information or education" (46.2\%; $n=66)$, "Had no opportunity" (29.3\%; n=42), and "Do not know what kind of education or information I need" (14.0\%; n=20) (Table 3). 
Table 2. Educational Needs According to the General Characteristics of the Participants, and Their Children's General and Diseaserelated Characteristics

$(N=171)$

\begin{tabular}{|c|c|c|c|c|c|c|}
\hline Variables & Characteristics & Categories & $\mathrm{n}(\%)$ & $\mathrm{M} \pm \mathrm{SD}$ & $\mathrm{t}$ or $\mathrm{F}$ & $p$ \\
\hline \multirow{26}{*}{$\begin{array}{l}\text { Participant's general } \\
\text { characteristics }\end{array}$} & Relationship with the child & Mother & $127(74.3)$ & $3.47 \pm 0.58$ & 0.05 & .961 \\
\hline & & Father & $44(25.7)$ & $3.48 \pm 0.51$ & & \\
\hline & Age (year) & $20 \sim 29$ & $22(12.9)$ & $3.50 \pm 0.67$ & 0.28 & .753 \\
\hline & & $30 \sim 39$ & $135(78.9)$ & $3.46 \pm 0.54$ & & \\
\hline & & $\geq 40$ & $14(8.2)$ & $3.57 \pm 0.51$ & & \\
\hline & & $\mathrm{M} \pm \mathrm{SD}$ & $34.4 \pm 3.9$ & & & \\
\hline & Level of education & $\leq$ High school & $17(9.9)$ & $3.65 \pm 0.49$ & 1.47 & .226 \\
\hline & & College & $49(28.7)$ & $3.53 \pm 0.58$ & & \\
\hline & & Bachelor's degree & $97(56.7)$ & $3.40 \pm 0.55$ & & \\
\hline & & $\geq$ Master's degree & $8(4.7)$ & $3.63 \pm 0.52$ & & \\
\hline & Employed & Yes & $64(37.4)$ & $3.48 \pm 0.53$ & 0.19 & .847 \\
\hline & & No & $107(62.6)$ & $3.47 \pm 0.57$ & & \\
\hline & Classification of occupation $(n=64)$ & Managers & $1(1.6)$ & $4.00 \pm 0.00$ & 0.45 & .813 \\
\hline & & Professionals & $12(18.8)$ & $3.58 \pm 0.52$ & & \\
\hline & & Clerks & $29(45.2)$ & $3.45 \pm 0.51$ & & \\
\hline & & Service workers & $9(14.1)$ & $3.33 \pm 0.50$ & & \\
\hline & & Sale workers & $11(17.2)$ & $3.55 \pm 0.69$ & & \\
\hline & & Craft workers & $2(3.1)$ & $3.50 \pm 0.71$ & & \\
\hline & Income $(10,000$ won per month) & $\leq 200$ & $11(6.4)$ & $3.45 \pm 0.52$ & 0.29 & .628 \\
\hline & & $201 \sim 400$ & $85(49.7)$ & $3.44 \pm 0.59$ & & \\
\hline & & $\geq 401$ & $75(43.9)$ & $3.52 \pm 0.53$ & & \\
\hline & Number of children & 1 & $105(61.4)$ & $3.43 \pm 0.54$ & 1.25 & .290 \\
\hline & & 2 & $54(31.6)$ & $3.52 \pm 0.57$ & & \\
\hline & & $\geq 3$ & $12(7.0)$ & $3.67 \pm 0.65$ & & \\
\hline & Residential area & Urban & $161(94.2)$ & $3.47 \pm 0.56$ & 0.15 & .878 \\
\hline & & Rural & $10(5.8)$ & $3.50 \pm 0.53$ & & \\
\hline \multirow{30}{*}{$\begin{array}{l}\text { Child's general and } \\
\text { disease-related } \\
\text { characteristics }\end{array}$} & Sex & Male & 87 (50.9) & $3.49 \pm 0.53$ & 0.49 & .624 \\
\hline & & Female & $84(49.1)$ & $3.45 \pm 0.59$ & & \\
\hline & Age (month) & $2 \sim 12$ & $32(18.7)$ & $3.59 \pm 0.50$ & 1.36 & .177 \\
\hline & & $13 \sim 36$ & $139(81.3)$ & $3.45 \pm 0.57$ & & \\
\hline & Order & 1st & $118(69.0)$ & $3.43 \pm 0.55$ & 2.56 & .081 \\
\hline & & 2nd & 45 (26.3) & $3.51 \pm 0.59$ & & \\
\hline & & $\geq 3 \mathrm{rd}$ & $8(4.7)$ & $3.88 \pm 0.35$ & & \\
\hline & Caregiver & Mother & $147(86.0)$ & $3.49 \pm 0.57$ & 0.53 & .662 \\
\hline & & Father & $5(2.9)$ & $3.20 \pm 0.45$ & & \\
\hline & & Grand parents & $15(8.8)$ & $3.40 \pm 0.51$ & & \\
\hline & & Helper & $4(2.3)$ & $3.50 \pm 0.58$ & & \\
\hline & Classification of $\mathrm{CHD}^{\dagger}(\mathrm{n}=158)$ & Acyanotic $^{\dagger}$ & $109(69.0)$ & $3.43 \pm 0.55$ & 2.38 & .019 \\
\hline & & Cyanotic $^{\S}$ & $49(31.0)$ & $3.65 \pm 0.52$ & & \\
\hline & Number of medical interventions & None $^{a}$ & $48(28.1)$ & $3.33 \pm 0.48$ & 7.83 & .001 \\
\hline & & & $75(43.8)$ & $3.40 \pm 0.62$ & & $a, b<c^{*}$ \\
\hline & & $\geq 2^{c}$ & $48(28.1)$ & $3.73 \pm 0.45$ & & \\
\hline & Timing of the first medical intervention & Neonate $^{a}$ & $28(22.8)$ & $3.75 \pm 0.44$ & 4.82 & .010 \\
\hline & (month) $(\mathrm{n}=123)$ & $2 \sim 12^{\mathrm{b}}$ & $72(58.5)$ & $3.53 \pm 0.56$ & & $a>c^{*}$ \\
\hline & & $13 \sim 36^{c}$ & $23(18.7)$ & $3.26 \pm 0.69$ & & \\
\hline & Timing of the last medical & Neonate & $1(2.1)$ & $4.00 \pm 0.00$ & 0.20 & .820 \\
\hline & intervention (month) $(\mathrm{n}=48)$ & $2 \sim 12$ & $30(62.5)$ & $3.73 \pm 0.45$ & & \\
\hline & & $13 \sim 36$ & $17(35.4)$ & $3.71 \pm 0.47$ & & \\
\hline & Time passed after discharge (month) & $\leq 1$ & $40(23.4)$ & $3.53 \pm 0.60$ & 0.14 & .797 \\
\hline & & $2 \sim 12$ & $69(40.3)$ & $3.46 \pm 0.56$ & & \\
\hline & & $\geq 12$ & $62(36.3)$ & $3.45 \pm 0.53$ & & \\
\hline & Current medication status $^{\dagger}(n=161)$ & Yes & $70(43.5)$ & $3.73 \pm 0.48$ & 4.90 & $<.001$ \\
\hline & & No & $91(56.5)$ & $3.34 \pm 0.52$ & & \\
\hline & Additional medical interventions & Yes $^{a}$ & $34(19.9)$ & $3.79 \pm 0.41$ & 7.66 & .001 \\
\hline & scheduled & $\mathrm{No}^{\mathrm{b}}$ & $104(60.8)$ & $3.40 \pm 0.51$ & & \\
\hline & & Unknown $^{c}$ & $33(19.3)$ & $3.36 \pm 0.70$ & & \\
\hline
\end{tabular}

*Scheffé test, $p<.050 ;{ }^{\dagger}$ Missing data were not included; ${ }^{\dagger}$ Ventricular/atrial septal defect, patent ductus arteriosus, atrioventricular septal defect, stenosis/ coarctation of the aorta, mitral stenosis; ${ }^{\S}$ Tetralogy of Fallot, stenosis/atresia of pulmonary artery, anomalous pulmonary venous connection, tricuspid atresia, double outlet right ventricle, hypoplastic left heart syndrome, transposition of great arteries, interrupted aortic arch; $\mathrm{CHD}=\mathrm{Congenital}$ heart disease. 
Table 3. Experiences of the Participants Regarding Education on Managing the Disease of a Child with Congenital Heart Disease

$(N=171)$

\begin{tabular}{|c|c|c|}
\hline Characteristics & Categories & $\mathrm{n}(\%)$ or $\mathrm{M} \pm \mathrm{SD}$ \\
\hline Education experience related to & Yes & $28(16.4)$ \\
\hline CHD after discharge & No & $143(83.6)$ \\
\hline Source of information* $(n=28)$ & $\begin{array}{l}\text { Off-line large-group education } \\
\text { Off-line small-group education } \\
\text { Off-line one-on-one education } \\
\text { TV program } \\
\text { Blog or online community } \\
\text { SNS } \\
\text { YouTube } \\
\text { Hospital website or heart foundation website } \\
\text { Other website } \\
\text { Application } \\
\text { Paper } \\
\text { Book or pamphlet } \\
\text { Acquaintance }\end{array}$ & $\begin{aligned} 10 & (35.7) \\
7 & (25.0) \\
6 & (21.4) \\
4 & (14.3) \\
12 & (42.9) \\
9 & (32.1) \\
10 & (35.7) \\
15 & (53.6) \\
2 & (7.1) \\
0 & (0.0) \\
2 & (7.1) \\
2 & (7.1) \\
4 & (14.3)\end{aligned}$ \\
\hline $\begin{array}{l}\text { The most satisfying source of } \\
\text { information }(n=28)\end{array}$ & $\begin{array}{l}\text { Off-line large-group education } \\
\text { Off-line small-group education } \\
\text { Off-line one-on-one education } \\
\text { TV program } \\
\text { Blog or online community } \\
\text { SNS } \\
\text { YouTube } \\
\text { Hospital website or heart foundation website } \\
\text { Paper } \\
\text { Acquaintance }\end{array}$ & $\begin{array}{l}6(21.5) \\
4(14.3) \\
4(14.3) \\
2(7.1) \\
2(7.1) \\
2(7.1) \\
2(7.1) \\
4(14.3) \\
1(3.6) \\
1(3.6)\end{array}$ \\
\hline Satisfaction with education $(n=28)$ & & $2.89 \pm 0.57$ \\
\hline $\begin{array}{l}\text { Reasons for not receiving } \\
\text { education }(n=143)\end{array}$ & $\begin{array}{l}\text { Had no time } \\
\text { Had no opportunity } \\
\text { No information or education } \\
\text { Think that it is not necessary } \\
\text { Do not know what kind of education or information I need }\end{array}$ & $\begin{aligned} & 1 \\
42 & (7.7) \\
66 & (46.2) \\
4 & (2.8) \\
20 & (14.0)\end{aligned}$ \\
\hline
\end{tabular}

*Multiple response item (percent of respondents); $\mathrm{CHD}=$ Congenital heart disease; $\mathrm{SNS}=$ Social networking services.

3) Preferences for education on managing their children's disease after hospital discharge

Almost all $(97.1 \%$; $=166)$ of the parents responded that education on managing their children's disease after hospital discharge is necessary, with $50.3 \%(n=86)$ indicating that it is "very necessary" and $46.8 \%(n=80)$ responding that it is "necessary". The most preferred source of information was direct, offline education (57.9\%; $\mathrm{n}=99)$. Among specific methods of offline education, the most preferred was small-group education $(26.3 \% ; n=45)$, followed by one-on-one education $(21.1 \% ; n=36)$ and large-group education $(10.5 \% ; n=18)$. Among online education methods, $12.9 \%(n=22)$ of participants preferred YouTube and $9.4 \%(n=16)$ smartphone applications. Only a few parents selected websites $(2.3 \% ; n=4)$ and booklets/pamphlets $(2.3 \% ; n=4)$ as their preferred educational methods. The average preference score was highest for questions and answers (Q\&A) (3.43 \pm 0.71$)$, followed by case $(3.40 \pm$ $0.67)$, videos $(3.26 \pm 0.75)$, and pictures $(3.18 \pm 0.70)$. The majority $(77.8 \% ; \mathrm{n}=133)$ of parents responded that pediatric cardiologists should develop the educational materials, while $48.5 \%(n=83)$ and $45.6 \%(n=78)$ responded that professors of pediatrics or pediatric nursing and pediatric cardiology nurses, respectively, should do so (Table 4).

\section{4) Educational needs for children's disease management after hospital discharge according to informational content}

The average overall score for educational needs on disease management of children with $\mathrm{CHD}$ was 3.39 (SD=0.39). Categories with high scores were symptoms and responses (3.51 $\pm 0.46)$, the prognosis of $\mathrm{CHD}(3.48 \pm 0.49)$, and the growth and 
Table 4. Preferences of the Participants for Education on Managing the Disease of a Child with Congenital Heart Disease ( $N=171)$

\begin{tabular}{|c|c|c|}
\hline Characteristics & Categories & $\mathrm{n}(\%)$ or $\mathrm{M} \pm \mathrm{SD}$ \\
\hline Necessity of education & $\begin{array}{l}\text { Very necessary } \\
\text { Necessary } \\
\text { Unnecessary } \\
\text { Not necessary at all }\end{array}$ & $\begin{array}{c}86(50.3) \\
80(46.8) \\
5(2.9) \\
0(0.0)\end{array}$ \\
\hline Preferred source of information & $\begin{array}{l}\text { Off-line large-group education } \\
\text { Off-line small-group education } \\
\text { Off-line one-on-one education } \\
\text { TV program } \\
\text { Blog or online community } \\
\text { SNS } \\
\text { YouTube } \\
\text { Website } \\
\text { Application } \\
\text { Book or pamphlet }\end{array}$ & $\begin{aligned} 18 & (10.5) \\
45 & (26.3) \\
36 & (21.1) \\
7 & (4.1) \\
12 & (7.0) \\
7 & (4.1) \\
22 & (12.9) \\
4 & (2.3) \\
16 & (9.4) \\
4 & (2.3)\end{aligned}$ \\
\hline Preferred method of education & $\begin{array}{l}\text { Instructor-led information } \\
\text { Video } \\
\text { Written material } \\
\text { Picture } \\
\text { Case } \\
\text { Q\&A }\end{array}$ & $\begin{array}{l}3.14 \pm 0.68 \\
3.26 \pm 0.75 \\
2.99 \pm 0.79 \\
3.18 \pm 0.70 \\
3.40 \pm 0.67 \\
3.43 \pm 0.71\end{array}$ \\
\hline $\begin{array}{l}\text { Preferred developer or instructor } \\
\text { of the educational program* }\end{array}$ & $\begin{array}{l}\text { Pediatric cardiologist } \\
\text { Pediatric cardiology nurse } \\
\text { Professor of pediatrics or pediatric nursing } \\
\text { Cardiac rehabilitation related health professor } \\
\text { Parents of children with CHD } \\
\text { Others }^{\dagger}\end{array}$ & $\begin{array}{c}133(77.8) \\
78(45.6) \\
83(48.5) \\
49(28.7) \\
37(21.6) \\
1(0.6)\end{array}$ \\
\hline
\end{tabular}

*Multiple response item (percent of respondents); ${ }^{\dagger}$ Child psychologist; SNS=Social networking services; $\mathrm{Q} \& \mathrm{~A}=\mathrm{Question}$ and answer; $\mathrm{CHD}=\mathrm{Congenital}$ heart disease.

development (3.45 \pm 0.45$)$. The highest score for any single item was reported for symptoms and response to cyanosis (3.61 \pm 0.60$)$, followed by the effects of $\mathrm{CHD}$ on the growth and development of infants and toddlers, symptoms and responses to dyspnea or shortness of breathing, and the adequate caloric intake and appropriate weight gain for infants and toddlers with CHD. Items with low need scores included medical devices used at home (3.23 \pm 0.59$)$, regular check- ups $(3.29 \pm 0.58)$, and surgical wound management $(3.30 \pm 0.57)$ (Table 5). The open-ended item eliciting information on educational content that participants were curious about was analyzed, and the responses could be categorized into general aspects about $\mathrm{CHD}$, the prognosis of $\mathrm{CHD}$, symptoms of $\mathrm{CHD}$ and responses, regular check-ups, and growth and development.

\section{DISCUSSION}

Almost all (97.1\%) of the parents of infants and toddlers with $\mathrm{CHD}$ in this study responded that they perceived education on the management of their children's disease after discharge to be necessary. The need for education was higher among parents whose children had cyanotic CHD, had experienced two or more treatment interventions, had experienced treatment interventions as newborns, were currently on medication, and were scheduled for further treatment interventions, all of which are characteristics related to the child's disease severity. Svavardottir and McCubbin [22] reported a statistically significant association between disease severity in infants with CHD and parents' understanding of their children's disease management situation as a parental coping pattern. It is speculated that when infants and toddlers are affected by severe disease, their parents have a high need for education in order to understand how to manage their children's disease. Kim [23] also found that parents of children with complicated and severe CHD had lower levels of adjustment and higher levels of stress, calling for special attention be given to this population. Since providing information to parents of children with CHD reduces parenting stress and helps them accept their children's diseases [14,15], adequate informational support should be provided to parents of children with severe CHD in order to alleviate their stress and facilitate their adjustment.

Only $16.4 \%$ of parents responded that they had received ed- 
Table 5. Educational Needs of the Participants According to Informational Content

\begin{tabular}{|c|c|c|}
\hline Categories/ item & $\mathrm{M} \pm \mathrm{SD}$ & Order \\
\hline $\begin{array}{l}\text { General aspects of CHD } \\
\text { 1. Normal structure of the cardiovascular system } \\
\text { 2. Normal function of the cardiovascular system } \\
\text { 3. Classification and definition of CHD } \\
\text { 4. Etiology of CHD } \\
\text { 5. Symptoms of CHD } \\
\text { 6. Treatment of CHD } \\
\text { 7. Diagnostic and therapeutic methods of CHD }\end{array}$ & $\begin{array}{l}3.39 \pm 0.42 \\
3.26 \pm 0.61 \\
3.20 \pm 0.69 \\
3.53 \pm 0.62 \\
3.40 \pm 0.71 \\
3.47 \pm 0.64 \\
3.39 \pm 0.67 \\
3.44 \pm 0.69\end{array}$ & $\begin{array}{c}7 \\
49 \\
54 \\
6 \\
28 \\
13 \\
33 \\
20\end{array}$ \\
\hline $\begin{array}{l}\text { Prognosis of CHD } \\
\text { 8. Surgical or long-term survival rate according to each disease } \\
\text { 9. Probability of giving birth to another child with CHD } \\
\text { 10. Additional medical intervention (surgery or catheterization) }\end{array}$ & $\begin{array}{l}3.48 \pm 0.49 \\
3.47 \pm 0.68 \\
3.51 \pm 0.65 \\
3.46 \pm 0.66\end{array}$ & $\begin{array}{c}2 \\
16 \\
8 \\
18\end{array}$ \\
\hline $\begin{array}{l}\text { Surgical wound management } \\
\text { 11. Surgical wound care at home } \\
\text { 12. Surgical wound management at home } \\
\text { 13. The timing of when babies can be bathed after surgery } \\
\text { 14. How to bathe after surgery }\end{array}$ & $\begin{array}{l}3.30 \pm 0.57 \\
3.29 \pm 0.72 \\
3.30 \pm 0.71 \\
3.29 \pm 0.76 \\
3.30 \pm 0.72\end{array}$ & $\begin{array}{l}11 \\
45 \\
43 \\
44 \\
41\end{array}$ \\
\hline $\begin{array}{l}\text { Postoperative respiratory therapy } \\
\text { 15. Reasons for chest percussion and the vibration technique } \\
\text { 16. How to perform chest percussion and the vibration technique } \\
\text { 17. Introduction and usage of a nebulizer } \\
\text { 18. How to clean a nebulizer }\end{array}$ & $\begin{array}{l}3.40 \pm 0.49 \\
3.46 \pm 0.65 \\
3.43 \pm 0.63 \\
3.28 \pm 0.67 \\
3.42 \pm 0.67\end{array}$ & $\begin{array}{l}6 \\
17 \\
21 \\
47 \\
24\end{array}$ \\
\hline $\begin{array}{l}\text { Medications } \\
\text { 19. Name and classification of the medication } \\
\text { 20. Purpose of the medication (therapeutic effect) } \\
\text { 21. How long to take the medication } \\
\text { 22. How to take the medication (schedule and dosage) } \\
\text { 23. Adverse effects of the medication } \\
\text { 24. Other medications to be avoided due to drug-drug interactions }\end{array}$ & $\begin{array}{l}3.34 \pm 0.52 \\
3.34 \pm 0.68 \\
3.28 \pm 0.70 \\
3.26 \pm 0.74 \\
3.21 \pm 0.76 \\
3.50 \pm 0.61 \\
3.43 \pm 0.77\end{array}$ & $\begin{array}{l}10 \\
38 \\
46 \\
50 \\
53 \\
10 \\
22\end{array}$ \\
\hline $\begin{array}{l}\text { Symptoms and responses } \\
\text { 25. Cyanosis } \\
\text { 26. Fever } \\
\text { 27. Edema and decreased urine output } \\
\text { 28. Dyspnea and shortness of breathing } \\
\text { 29. Feeding problems (poor feeding, sweating during feeding, etc.) }\end{array}$ & $\begin{array}{l}3.51 \pm 0.46 \\
3.61 \pm 0.60 \\
3.47 \pm 0.61 \\
3.53 \pm 0.65 \\
3.53 \pm 0.70 \\
3.40 \pm 0.68\end{array}$ & $\begin{array}{c}1 \\
1 \\
15 \\
7 \\
3 \\
31\end{array}$ \\
\hline $\begin{array}{l}\text { Regular check-ups } \\
\text { 30. The timing of regular check-up } \\
\text { 31. Examinations to be performed during regular check-up }\end{array}$ & $\begin{array}{l}3.29 \pm 0.58 \\
3.31 \pm 0.66 \\
3.27 \pm 0.66\end{array}$ & $\begin{array}{l}12 \\
40 \\
48\end{array}$ \\
\hline $\begin{array}{l}\text { Complications of CHD } \\
\text { 32. Definition and symptoms of endocarditis } \\
\text { 33. Prevention of endocarditis } \\
\text { 34. Reasons for preventative dental care } \\
\text { 35. How to manage the child's dental care }\end{array}$ & $\begin{array}{l}3.37 \pm 0.49 \\
3.44 \pm 0.64 \\
3.49 \pm 0.61 \\
3.32 \pm 0.71 \\
3.22 \pm 0.78\end{array}$ & $\begin{array}{c}8 \\
19 \\
11 \\
39 \\
52\end{array}$ \\
\hline $\begin{array}{l}\text { Feeding and nutrition } \\
\text { 36. Adequate caloric intake and appropriate weight gain for infants and toddlers with CHD } \\
\text { 37. Characteristics related to feeding for infants and toddlers with } \mathrm{CHD} \\
\text { 38. Feeding management for infants and toddlers with CHD } \\
\text { 39. Breastfeeding for infants and toddlers with CHD } \\
\text { 40. Information related to food intake for infants and toddlers with CHD } \\
\text { 41. Management of the feeding tube }\end{array}$ & $\begin{array}{l}3.35 \pm 0.47 \\
3.53 \pm 0.63 \\
3.35 \pm 0.69 \\
3.20 \pm 0.73 \\
3.25 \pm 0.79 \\
3.40 \pm 0.71 \\
3.36 \pm 0.67\end{array}$ & $\begin{array}{l}9 \\
4 \\
37 \\
55 \\
51 \\
28 \\
36\end{array}$ \\
\hline $\begin{array}{l}\text { Growth and development } \\
\text { 42. Immunization after open heart surgery } \\
\text { 43. Considerations for the immunization of infants and toddlers with CHD } \\
\text { 44. Effects of CHD on the growth and development of infants and toddlers with CHD } \\
\text { 45. The development of normal infant and toddlers } \\
\text { 46. Physical activity of infant and toddlers with CHD }\end{array}$ & $\begin{array}{l}3.45 \pm 0.45 \\
3.40 \pm 0.65 \\
3.42 \pm 0.69 \\
3.60 \pm 0.59 \\
3.37 \pm 0.67 \\
3.49 \pm 0.72\end{array}$ & $\begin{array}{c}3 \\
30 \\
26 \\
2 \\
34 \\
12\end{array}$ \\
\hline $\begin{array}{l}\text { Cardiac rehabilitation in CHD } \\
\text { 47. Case requiring cardiac rehabilitation } \\
\text { 48. Cardiac rehabilitation in infant and toddlers with CHD }\end{array}$ & $\begin{array}{l}3.45 \pm 0.51 \\
3.47 \pm 0.64 \\
3.42 \pm 0.58\end{array}$ & $\begin{array}{c}4 \\
13 \\
25\end{array}$ \\
\hline $\begin{array}{l}\text { Medical devices used at home } \\
\text { 49. Pulse oximetry } \\
\text { 50. Thermometer }\end{array}$ & $\begin{array}{l}3.23 \pm 0.59 \\
3.30 \pm 0.69 \\
3.16 \pm 0.75\end{array}$ & $\begin{array}{l}13 \\
42 \\
56\end{array}$ \\
\hline $\begin{array}{l}\text { Information that the family of a child with CHD should know } \\
\text { 51. When to call the doctor (symptoms and signs) } \\
\text { 52. CPR for infants and toddlers } \\
\text { 53. Hospital information for CHD } \\
\text { 54. Information on babies with CHD to be provided to the health care provider during hospital visits } \\
\text { 55. Travel-related information } \\
\text { 56. Home monitoring }\end{array}$ & $\begin{array}{l}3.44 \pm 0.44 \\
3.39 \pm 0.63 \\
3.53 \pm 0.63 \\
3.37 \pm 0.70 \\
3.42 \pm 0.63 \\
3.42 \pm 0.68 \\
3.53 \pm 0.65\end{array}$ & $\begin{array}{l}5 \\
32 \\
4 \\
35 \\
23 \\
27 \\
8\end{array}$ \\
\hline
\end{tabular}

$\mathrm{CHD}=$ Congenital heart disease; $\mathrm{CPR}=$ Cardiopulmonary resuscitation. 
ucation on their children's disease management after hospital discharge. The overall satisfaction score for the education that they had received was 2.89, a little lower than "satisfactory". Parents mostly received education online through hospital websites or heart foundation websites, blogs and online communities, YouTube, and SNS. This result is similar to the findings reported by Lee and Yoo [14] and Youn [15] that caretakers of children with CHD usually received information online, as well as the results of the in-depth interviews conducted in this study. However, the parents in Youn's study [15] and parents who participated in the in-depth interviews regarded the information they found online to be unprofessional or unreliable. Relatedly, although online educational sources were those that respondents had most commonly experienced, offline educational sources were preferred and received high satisfaction scores. Previous research in South Korea that evaluated the quality of online health information for infants and toddlers pointed out that despite the large volume of health information online, only a small fraction of the information is practically useful since the reliability and quality of the information is low [24]. However, the in-depth interviews revealed a critical need for information that is easy to access at home since parents of infants and toddlers with CHD need to provide constant care for their children. The internet also provides a convenient way to communicate with other parents in similar situations [25]. Thus, it can be predicted that the number of parents obtaining information online will not decrease. Therefore, accurate and reliable online education materials should be developed. Interactive online parental education using SNS platforms can meet parents' needs, since these platforms enable parents to ask questions and receive real-time answers through information provided by the instructor and to share their experiences without time or geographic limitations.

The average score for educational needs for managing their children's disease after hospital discharge was 3.39 out of 4 , which was slightly lower than the score of 4.69 out of 5 for educational needs upon discharge reported by Lee and Jo [13], in a study of mothers of hospitalized children (aged 1 to 16). This discrepancy may be explained by the finding that parents' level of comfort increases after hospital discharge compared to before discharge [18], since the present study was conducted among parents of infants and toddlers who had already been discharged. A direct comparison is difficult due to the difference in study populations, so it is recommended to develop a stepwise discharge education program that incorporates an understanding of the educational needs and anxiety of parents of children with CHD both before and after discharge.

In terms of educational content, parents were most curious about understanding and responding to symptoms that arise from their children's disease, their children's prognosis, and the effects of the disease on their children's growth and development. On the other hand, low scores were reported for educational needs for regular check-ups and surgical wound management, the results of in-depth interviews suggest that hospitals continue to provide information about regular check-ups and guidance on surgical wound management via phone calls or text messages. In particular, since hospitals already arrange for parents to be able to call nurses and ask about surgical wound management after discharge, the perceived need for this content was low. Therefore, the information provided after hospital discharge should focus on the information that parents need at home (e.g., symptoms and responses, prognosis, and growth and development of infants and toddlers with $\mathrm{CHD}$ ).

First, the highest score for educational needs was found for the item on symptoms and responses of CHD. The results of a previous study of parents of infants recruited from 11 heart centers in Great Britain suggested that most parents were not ready for discharge and felt fearful due to the lack of the information they would need to notice deterioration of their infants' disease [11]. Similar to the results from this study, prior research conducted in South Korea reported that parents of children with CHD expressed needs for education on cyanosis, changes in respiratory patterns, and the necessary responses [17]. In the in-depth interviews, parents expressed confusion about the symptoms of cyanosis since the word is explicitly connected to the color blue. Parents wondered whether their child would appear blue. A study by Tregay et al. [10] reported that mothers used colors such as blue, purple, grey, and yellow when they described their experiences of children's cyanosis and suggested that using the term "cyanosis" may be confusing for parents. Therefore, future post-hospital educational programs should include adequate information about cyanosis and changes in respiratory patterns. The information should be in plain language that can be understood by parents, and should utilize video or pictorial resources.

The second highest score for educational needs was found for the prognosis of CHD. In the in-depth interviews, parents were curious about the specific survival rates of various diseases and the probability that their next child would have CHD. The item 'Probability of giving birth to another child with CHD' was also highly endorsed in the survey. This result may have been due to the fact that $61.4 \%$ of the participating parents had one child, and the participants-as parents of infants and toddlers-were still of reproductive age. Park [17] also found that parents of children with $\mathrm{CHD}$ were curious about the probability that they would have another child with $\mathrm{CHD}$, suggesting the need to provide information about this 
possibility. The item "Surgical or long-term survival rate according to each disease" received a high score for educational needs, but the item received a CVI lower than .80 from experts in their review of the items for content validity. In contrast to the opinions of professional medical staff, parents showed a preference for having objective numbers to predict the uncertain future. This discrepancy suggests a gap between the educational content that medical professionals regarded as necessary and the educational content that parents actually wanted. Therefore, when educational programs for parents are set up, input should be sought not only from medical professionals, but also from the actual participants (i.e., parents).

The growth and development was another item that received a high score for educational needs. Specifically, parents frequently requested education about the effects of CHD on their children's growth and development and about physical activity. Parents who provide care to infants and toddlers with CHD at home constantly encounter these issues. Since for children with CHD, motor development is more prominently affected during infancy and early childhood than cognitive development [26], the results from the in-depth interviews suggest that the parents were concerned about delays in their children's motor development. However, the parents found it difficult to obtain information about this topic from sources other than other parents in similar situations. Since early interventions are important due to the poor prognosis of CHD patients when development is delayed in infancy [27], accurate information about the development of children with CHD should be conveyed to parents. With the recent trend for treatment interventions to be performed earlier, it has been reported that developmental delays are possible not only in patients with cyanotic and complicated CHD, but also in those who undergo open-heart surgery before the age of 1 [26]. Thus, information about the evaluation, management, and periodic re-evaluation of the neurological development of infants and toddlers with CHD should be provided. Feeding and eating are important for the growth of infants and toddlers with CHD. Therefore, to promote the growth and development of children with CHD, it will be important to provide parents with education on appropriate weight gain and the importance of feeding and nutritional intake. Specific guidelines $[9,16]$ on feeding methods for infants with CHD should also be provided. A high level of need was also reported for education on the physical activity of infants and toddlers. In the in-depth interviews, parents shared that their children experienced symptoms during physical activities and expressed their sense that guidelines for the level of physical activity are necessary. Although motor skills rapidly develop during infancy and early childhood, the risk involved in physical activity is not high since children engage in floor- based play in in- fancy [28]; furthermore, in toddlerhood, children can regulate the level of their physical activity appropriately and do not engage in competitive physical activities [29]. Education about limiting physical activity should be provided accordingly so parents do not restrict children from engaging in the level of physical activity necessary for growth and development in infancy and early childhood.

The parents who participated in this study responded that there were not enough opportunities for education after hospital discharge and expressed interest in receiving education during this period. Therefore, educational materials and programs that can be used by parents at home after hospital discharge should be developed and implemented.

\section{CONCLUSION}

The following conclusions were obtained by exploring the educational needs of parents of infants and toddlers with CHD after hospital discharge through in-depth interviews and online surveys. In the in-depth interviews, the parents indicated that they wanted reliable information, easy-to-understand information that incorporates visuals and case, and accessible and open information given the lack of education useful at home. The online survey found that only $16.4 \%$ of parents had received education on managing their children's $\mathrm{CHD}$ at home after discharge, and the most common reason for which parents did not receive education on this topic was that they did not have any information or education. The overwhelming majority (97.1\%) of parents endorsed the necessity of an educational program for use at home after discharge. Educational needs were especially high among the parents of children with severe CHD. Parents preferred the educational method of Q\&A in an offline setting and wanted doctors and nurses in the field of pediatric cardiology, and professors of pediatrics and pediatric nursing to develop the educational materials. Educational needs were high for information about the symptoms and responses of $\mathrm{CHD}$, the prognosis of CHD, and the growth and development of infants and toddlers with CHD.

In this study, a gap was found between the education that medical personnel considered to be necessary and the education that parents wanted. Therefore, a post-hospital educational program and information outlets that address the educational needs of parents of infants and toddlers with CHD should be developed.

\section{Conflict of interest}

No existing or potential conflict of interest relevant to this article was reported. 


\section{REFERENCES}

1. Centers for Disease Control and Prevention. Data and statistics on congenital heart defects [Internet]. Atlanta: Centers for Disease Control and Prevention; 2019 [cited 2019 December 06]. Available from: https://www.cdc.gov/ncbddd/heartdefects/data.html

2. The Korea heart Foundation. 2018 Current status of cardiovascular disease surgery in South Korea [Internet]. Seoul: The Korea heart Foundation; 2019 [cited 2019 November 12]. Available from: http://www.heart.or.kr/korean/board/board_renew.php

3. Flocco SF, Lillo A, Dellafiore F, Goossens E. Congenital heart disease: The nursing care handbook. Switzerland: Springer International Publishing; 2019. https://doi.org/10.1007/978-3-319-78423-6

4. Azhar AS, AlShammasi ZH, Higgi RE. The impact of congenital heart diseases on the quality of life of patients and their families in Saudi Arabia: Biological, psychological, and social dimensions. Saudi Medical Journal. 2016;37(4):392-402. https://doi.org/10.15537/smj.2016.4.13626

5. Bertoletti J, Marx GC, Junior SPH, Pellanda LC. Quality of life and congenital heart disease in childhood and adolescence. Arquivos Brasileiros de Cardiologia. 2014;102(2):192-198.

https://doi.org/10.5935/abc.20130244

6. Staveski SL, Parveen VP, Madathil SB, Kools S, Franck LS. Parent education discharge instruction program for care of children at home after cardiac surgery in Southern India. Cardiology in the Young. 2016;26(6):1213-1220. https://doi.org/10.1017/S1047951115002462

7. Wray J, Maynard L. The needs of families of children with heart disease. Journal of Developmental and Behavioral Pediatrics. 2006; 27(1):11-17. https://doi.org/10.1097/00004703-200602000-00002

8. Woolf-King SE, Anger A, Arnold EA, Weiss SJ, Teitel D. Mental health among parents of children with critical congenital heart defects: A systematic review. Journal of American Heart Association. 2019;6(2):e004862. https://doi.org/10.1161/JAHA.116.004862

9. Nieves JA, Uzark K, Rudd NA, Strawn J, Schmelzer A, Dobrolet N. Interstage home monitoring after newborn first-stage palliation for hypoplastic left heart syndrome: Family education strategies. Critical Care Nurse. 2017;37(2):72-88. https://doi.org/10.4037/ccn2017763

10. Tregay J, Brown KL, Crowe S, Bull C, Knowles RL, Smith L, et al. Signs of deterioration in infants discharged home following congenital heart surgery in the first year of life: A qualitative study. Archives of Disease in Childhood. 2016;101(10):902-908. https://doi.org/10.1136/archdischild-2014-308092

11. Gaskin KL, Barron DJ, Daniels A. Parents' preparedness for their infants' discharge following first-stage cardiac surgery: Development of a parental early warning tool. Cardiology in the Young. 2016;26(7):1414-1424.
https://doi.org/10.1017/S1047951116001062

12. Moon JR. A correlation study regarding knowledge, stress and coping of parents of patients with congenital heart disease [master's thesis]. Seoul: Hanyang University; 2000. p. 1-64.

13. Lee KJ, Jo HS. Descriptive study on the development of educational program for mothers with children who have had open heart surgery in congenital heart disease. The Korean Journal of Rehabilitation Nursing. 2001;4(1):73-83.

14. Lee S, Yoo IY. Personal resource and parenting stress of mothers of children with congenital heart disease. Journal of Korean Academy of Child Health Nursing. 2007;13(1):73-80.

15. Youn MS. The experience of the mothers about powerlessness of children with congenital heart disease [master's thesis]. Seoul: Chung-Ang University; 2001. p. 1-89.

16. Hartman D, Medoff-Cooper B. Transition to home after neonatal surgery for congenital heart disease. The American Journal of Maternal/Child Nursing. 2012;37(2):95-100. https://doi.org/10.1097/NMC.0b013e318241dac1

17. Park JY. Development of educational material for parents of children with CHD [master's thesis]. Seoul: Yonsei University; 2005. p. $1-116$.

18. Stinson J, McKeever P. Mothers' information needs related to caring for infants at home following cardiac surgery. Journal of Pediatric Nursing. 1995;10(1):48-57. https://doi.org/10.1016/S0882-5963(05)80098-3

19. March S. Parents' perceptions during the transition to home for their child with a congenital heart defect: How can we support families of children with hypoplastic left heart syndrome? Journal for Specialists in Pediatric Nursing. 2017;22(3):e12185.

https://doi.org/10.1111/jspn.12185

20. Sandelowski M. Whatever happened to qualitative description? Research in Nursing and Health. 2000;23(4):334-340.

https://doi.org/10.1002/1098-240X(200008)23:4<334::AID-NUR 9>3.0.CO;2-G

21. Elo S, Kyngäs A. The qualitative content analysis process. Journal of Advanced Nursing. 2008;62(1):107-115 https://doi.org/10.1111/j.1365-2648.2007.04569.x

22. Svavarsdottir EK, McCubbin M. Parenthood transition for parents of an infant diagnosed with a congenital heart condition. Journal of Pediatric Nursing. 1996;11(4):207-216. https://doi.org/10.1016/S0882-5963(96)80093-5

23. Kim KN. Factors affecting adaptation in parents of newborn with congenital heart disease. The Korean Journal of Health Service Management. 2013;7(3):111-123. https://doi.org/10.1281/kshsm.2013.7.3.11

24. Son HM, Je M, Sohn YS. Quality evaluation of online health information related to young child. Child Health Nursing Research. 2018;24(1):91-100. https://doi.org/10.4094/chnr.2018.24.1.91

25. Davies S, Hall D. "Contact a family": Professionals and parents in partnership. Archives of Disease in Childhood. 2005;90(10):1053- 
1057. https://doi.org/10.1136/adc.2004.070706

26. Latal B. Neurodevelopmental outcomes of the child with congenital heart disease. Clinics in Perinatology. 2016;43(1):173-185.

https://doi.org/10.1016/j.clp.2015.11.012

27. Marino BS. New concepts in predicting, evaluating, and managing neurodevelopmental outcomes in children with congenital heart disease. Current Opinion in Pediatrics. 2013;25(5):574-578. https://doi.org/10.1097/MOP.0b013e328365342e

28. Tremblay M, Leblanc A, Carson V, Choquette L, Connor Gorber S,
Dillman, et al. Canadian physical activity guidelines for the early years (aged 0-4 years). Applied Physiology, Nutrition, and Metabolism. 2012;37(2):345-369. https://doi.org/10.1139/h2012-018

29. Longmuir P, Brothers J, de Ferranti S, Hayman L, Van Hare G, Matherne $G$, et al. Promotion of physical activity for children and adults with congenital heart disease: A scientific statement from the American Heart Association. Circulation. 2013;127(21):2147-2159. https://doi.org/10.1161/CIR.0b013e318293688f 